\title{
Acute hemodynamic effects of restrictive mitral annuloplasty in patients with end-stage heart failure: Analysis by pressure-volume relations
}

\author{
Sven A. F. Tulner, MD, ${ }^{\mathrm{a}, \mathrm{b}}$ Paul Steendijk, PhD, ${ }^{\mathrm{b}}$ Robert J. M. Klautz, MD, PhD, ${ }^{\text {a }}$ Jeroen J. Bax, MD, PhD, ${ }^{\mathrm{b}}$
} Michel I. M. Versteegh, MD, ${ }^{a}$ Ernst E. van der Wall, MD, PhD, and Robert A. E. Dion, MD ${ }^{\mathrm{a}}$

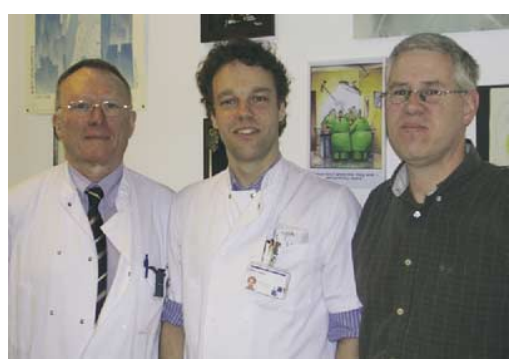

Dion, Tulner, Steendijk (left to right)
From the Departments of Cardio-Thoracic Surgery $^{\mathrm{a}}$ and Cardiology, ${ }^{\mathrm{b}}$ Leiden University Medical Center, Leiden, The Netherlands.

This study was supported by a grant from the Netherlands Heart Foundation (NHS2002B133).

Received for publication Oct 15, 2004; revisions received Dec 13, 2004; accepted for publication Dec 20, 2004

Address for reprints: Paul Steendijk, PhD, Leiden University Medical Center, Department of Cardiology, PO Box 9600, 2300RC Leiden, The Netherlands (E-mail: p.steendijk@lumc.nl)

J Thorac Cardiovasc Surg 2005;130:33-40

$0022-5223 / \$ 30.00$

Copyright $\odot 2005$ by The American Association for Thoracic Surgery

doi:10.1016/j.jtcvs.2004.12.019
Objective: Recent studies show beneficial long-term effects of restrictive mitral annuloplasty in patients with end-stage heart failure. However, concerns are raised about possible adverse effects on early postoperative systolic and diastolic function, which might limit application of this approach in patients with heart failure. Therefore we evaluated the acute effects of restrictive mitral annuloplasty on left ventricular function by using load-independent pressure-volume relations.

Methods: In 23 patients (heart failure, $\mathrm{n}=10$; control, $\mathrm{n}=13$ ) we determined left ventricular systolic and diastolic function before and after surgical intervention by means of pressure-volume analysis with a conductance catheter. All patients with heart failure underwent stringent restrictive mitral annuloplasty ( 2 sizes smaller than the measured size), and 4 received additional coronary artery bypass grafting. Transesophageal echocardiography was used for evaluation of valve repair. Patients with preserved left ventricular function who underwent isolated coronary artery bypass grafting served as control subjects.

Results: Restrictive mitral annuloplasty (ring size, $25 \pm 1$ ) restored leaflet coaptation $(8.0 \pm 0.2 \mathrm{~mm})$ with normal pressure gradients $(2.9 \pm 1.8 \mathrm{~mm} \mathrm{Hg})$. Restrictive mitral annuloplasty did not change cardiac output $(5.0 \pm 1.8$ to $5.3 \pm 0.9 \mathrm{~L} / \mathrm{min}, P$ $=.516)$, left ventricular ejection fraction $(29 \% \pm 5 \%$ to $32 \% \pm 8 \%, P=.315)$, or end-systolic elastance $(0.86 \pm 0.50$ to $0.99 \pm 1.05 \mathrm{~mm} \mathrm{Hg} / \mathrm{mL}, P=.688)$. After restrictive mitral annuloplasty, end-diastolic volume tended to decrease (237 \pm 89 to $226 \pm 52 \mathrm{~mL}, P=.564$ ), whereas end-diastolic pressure remained unchanged (14 \pm 6 to $15 \pm 5 \mathrm{~mm} \mathrm{Hg}, P=.356$ ). Diastolic chamber stiffness tended to increase $\left(0.027 \pm 0.035\right.$ to $\left.0.041 \pm 0.047 \mathrm{~mL}^{-1}, P=.542\right)$ but not significantly. Peak left ventricular wall stress was unchanged ( $356 \pm 91$ to $346 \pm 85 \mathrm{~mm} \mathrm{Hg}, P=.668$ ). Baseline values in the control group were different, but changes in most parameters after surgical intervention showed similar nonsignificant trends.

Conclusion: Mitral valve repair by means of restrictive mitral annuloplasty effectively restores mitral valve competence without inducing significant acute changes in left ventricular systolic or diastolic function in patients with end-stage heart failure.

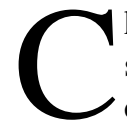
hronic mitral regurgitation is a serious complication in patients with endstage heart failure (HF). Patients with mitral regurgitation have a significantly decreased survival at 2 years' follow-up versus patients without mitral regurgitation. ${ }^{1}$

The mechanism of mitral regurgitation in end-stage HF is multifactorial. Briefly, it is related to changes in left ventricular (LV) geometry, with a subsequent displacement of the subvalvular apparatus, annular dilatation, ${ }^{2}$ and restrictive leaflet motion (class IIIb according to Carpentier's classification), ${ }^{3}$ which results in coap- 
tation failure. ${ }^{4,5}$ From a physiologic point of view, mitral regurgitation in these patients will lead to $\mathrm{LV}$ overload and reduction of forward stroke volume. This occurs initially in response to exercise and subsequently at rest, which in turn activates systemic and local neurohormonal systems and cytokines that worsen cardiac loading conditions and promote LV remodeling and dysfunction. ${ }^{6}$ This might create a vicious circle wherein regurgitation begets more regurgitation.

Previous studies have shown that interrupting this vicious cycle with mitral valve repair is safe and improves clinical outcome. ${ }^{7}$ Several groups advocate the use of a stringent restrictive ring, 2 sizes smaller than the measured size, to achieve better leaflet coaptation and possibly prevent recurrence of mitral regurgitation and promote reverse remodeling. ${ }^{8}$ Midterm results (18 months' follow-up) with this approach indicate reverse remodeling in $58 \%$ of patients. ${ }^{9}$ However, the acute effects of restrictive mitral annuloplasty (RMA) on LV systolic and diastolic function in patients with end-stage HF are unknown. There are concerns that correction of mitral regurgitation might decrease LV systolic function in the acute phase as a result of afterload increase caused by closure of a low-resistance runoff into the left atrium. In addition, it has been suggested that undersizing the mitral annulus might affect LV contractility because of increased mechanical tension on the base of the heart. ${ }^{10}$ With regard to diastolic function, RMA might impair filling. In contrast, Bolling and colleagues ${ }^{11}$ hypothesized that undersizing the mitral annulus will lead to acute beneficial geometric changes of the base of the left ventricle, which might reduce LV volume and wall stress. The purpose of this study was therefore to quantify the acute effects of RMA on global and intrinsic LV systolic and diastolic function in these patients.

\section{Material and Methods}

A total of 23 patients were studied in the operating room before and after cardiopulmonary bypass (CPB) by using pressure-volume analysis with the conductance catheter method. We included 10 patients with end-stage HF and coexistent severe mitral regurgitation who underwent mitral valve repair by means of stringent restrictive annuloplasty and 13 control patients with preserved LV function who underwent elective coronary artery bypass grafting (CABG). The control group was used to distinguish the effects of mitral annuloplasty from the effects of CPB and cardioplegic cardiac arrest per se. In both groups surgical intervention was performed during normothermic CPB with intermittent antegrade warm blood cardioplegia. The study protocol was approved by the institutional review board, and all patients provided informed written consent.

\section{Patient Selection and Echocardiographic Criteria}

The patients in the RMA group fulfilled the following criteria:

1. New York Heart Association class III or IV was present.

2. LV ejection fraction (LVEF) of less than $30 \%$ was present.
3. Mitral regurgitation of grade 2 or greater, as assessed by means of transesophageal echocardiography (TEE) preoperatively (without general anesthesia to avoid underestimation of the severity of the mitral regurgitation): The severity of mitral regurgitation was graded semiquantitatively on the basis of color-flow Doppler scanning and characterized as mild $(1+$; jet area/left atrial area of $<10 \%)$, moderate $(2+$; jet area/left atrial area of 10\%-20\%), moderately severe (3+; jet area/left atrial area of $20 \%-45 \%)$, and severe (4+; jet area/left atrial area of $>45 \%$ ). ${ }^{12}$ In patients with mitral regurgitation grade 2, an intraoperative dynamic loading test was performed, as described by Dion. ${ }^{5}$ If the result of this test was positive (ie, if it resulted in a definite worsening of the severity of mitral regurgitation), RMA was performed.

4. The mechanism of mitral regurgitation was based on malcoaptation caused by systolic restrictive motion of the mitral leaflets.

5. Maximal medical therapy for HF, including diuretics, afterload reduction, and $\beta$-blocking agents, was in use.

Patients with primary mitral valve dysfunction (mitral valve prolapse, rheumatic valve disease, and mitral valve stenosis) were excluded from the study. Also, patients with a previously implanted biologic or mechanical prosthesis in the aortic position were not included in this study.

The control group was recruited from patients with preserved LV function (LVEF > 40\%) who underwent elective CABG for multivessel coronary artery disease and who needed no additional valvular operations. The characteristics of both groups are summarized in Table 1.

\section{Anesthesia}

All patients received total intravenous anesthesia with targetcontrolled infusion of propofol, remifentanil, and sufentanil. Hypnotic state was monitored with a Bispectral Index monitor (Aspect Medical Systems, Newton, Mass). A single dose of pancuronium bromide $(0.1 \mathrm{mg} / \mathrm{kg})$ was given to facilitate intubation. During the operation, the propofol concentration was adjusted between 1.5 and $2.0 \mu \mathrm{g} / \mathrm{mL}$ to maintain a Bispectral Index value of less than 60. Remifentanil was titrated between 5 and $10 \mathrm{ng} / \mathrm{mL}$ in response to the patient's hemodynamic reaction to surgical stimuli. Sufentanil was started at a targeted concentration of $0.1 \mathrm{ng} / \mathrm{mL}$ after the start of the operation to allow smooth transition of the patient's analgesic state from the operating room to the intensive care unit. The patients were ventilated with an oxygen-air mixture (fraction of inspired oxygen of $40 \%$ ) at a ventilatory rate of 12 to 15 breaths/min, and ventilatory volume was adjusted to maintain normal $\mathrm{PaCO}_{2}$. A thermal filament catheter was placed in the pulmonary artery through the right internal jugular vein for semicontinuous thermodilution cardiac output measurements (Edwards Lifesciences, Uden, The Netherlands). A multiplane TEE probe was inserted to facilitate positioning of the conductance catheter and to evaluate the effects of mitral valve repair. We anticipated that the patients with HF would require inotropic support after surgical intervention. Because this would bias our LV function measurements, we started inotropic support directly after induction of anesthesia, with a low loading dose of $0.25 \mathrm{mg} / \mathrm{kg}$ enoximone in 10 minutes, and thereafter we provided continuous infusion at a 
rate of $0.50 \mu \mathrm{g} \cdot \mathrm{kg}^{-1} \cdot \mathrm{min}^{-1}$, which was maintained during the whole operation.

\section{Surgical Techniques}

After median sternotomy and, if indicated, harvesting of bypass material, the pericardium was opened, and normothermic CPB was instituted with intermittent antegrade warm blood cardioplegic arrest. ${ }^{13}$ After completion of the anastomosis, a stringent RMA was performed through a transseptal approach by using a Carpentier Edwards Physio-ring (Edwards Lifesciences). ${ }^{14}$ The ring size was determined by measuring the size of the anterior mitral leaflet, and a ring 2 sizes smaller than the measured size was implanted. After weaning from CPB, TEE evaluation was immediately performed in all patients to assess residual mitral regurgitation, transmitral diastolic pressure gradient (determined from continuouswave Doppler), and length of coaptation of the leaflets.

\section{Study Protocol}

Before and directly after CPB, conductance catheter measurements were performed, as described previously. ${ }^{15}$ Briefly, temporary epicardial pacemaker wires were placed on the right atrium to enable pre-CPB and post-CPB measurements at fixed equal heart rates. A tourniquet was placed around the inferior vena cava to enable temporary preload reductions. An $8 \mathrm{~F}$ sheath was placed in the ascending aorta for introduction of the conductance catheter. The conductance catheter was introduced under TEE guidance and placed along the long axis of the LV. The position was optimized through inspection of the segmental volume signals. Conductance catheter calibration was performed before and after CPB by using calibration factor $\alpha$, derived from thermodilution, and parallel conductance correction volume, determined by using the hypertonic saline method. ${ }^{16}$ At each stage, we performed at least 2 injections of $7 \mathrm{~mL}$ of $10 \%$ saline into the pulmonary artery through the distal port of the thermodilution catheter. Continuous LV pressure and volume signals derived from the conductance catheter were displayed and acquired at a $250-\mathrm{Hz}$ sampling rate with a Leycom CFL-512 (CD Leycom, Zoetermeer, The Netherlands). Data were acquired during steady-state conditions and during temporary caval vein occlusion, all with the ventilator turned off at end expiration. Acquisition was performed at a fixed atrial pacing rate of 80 beats/min. From these signals, hemodynamic indices were derived as described below.

\section{Pressure-volume Analysis}

Global LV function. Parameters of global systolic and diastolic function (heart rate, cardiac output, stroke volume, stroke work, pressure-volume area, LVEF, $\mathrm{dP} / \mathrm{dt}_{\mathrm{MAX}}, \mathrm{dP} / \mathrm{dt}_{\mathrm{MIN}}$, enddiastolic volume [EDV], end-systolic volume [ESV], end-diastolic pressure [EDP], end-systolic pressure [ESP], and relaxation constant Tau) were calculated from steady-state beats by using custom-made software. Mechanical dyssynchrony and internal flow fraction were calculated as previously described. ${ }^{17}$ Effective arterial elastance, a measure of afterload, was calculated as ESP/SV. Time-varying wall stress, WS(t), was calculated from the LV pressure and volume signals $(\mathrm{P}[\mathrm{t}], \mathrm{V}[\mathrm{t}])$, as described by Arts and associates $^{18}$ :
TABLE 1. Patient characteristics

\begin{tabular}{lcc}
\hline & RMA group & Control group \\
\hline No. of patients & 10 & 13 \\
Male/female sex & $5 / 5$ & $11 / 2$ \\
Age (y) & $56 \pm 18$ & $63 \pm 8$ \\
NYHA class & $3.6 \pm 0.5$ & - \\
LVEF (\%) & $25 \pm 5$ & $58 \pm 9$ \\
Mitral regurgitation (grade) & $3.3 \pm 0.5$ & -
\end{tabular}

RMA, Restrictive mitral annuloplasty; NYHA, New York Heart Association; $L V E F$, left ventricular ejection fraction.

$$
W S(t)=P(t) \cdot\left[1+3 \cdot V(t) / V_{W A L L}\right]
$$

LV wall volume was estimated on the basis of the diastolic posterior wall thickness derived from M-mode echocardiography. The gradient across the LV outflow tract was calculated as the difference between peak LV pressure and peak aortic pressure.

Systolic and diastolic LV pressure-volume relations. Systolic function was characterized by the slope of the end-systolic pressure-volume relation (end-systolic elastance), the slope of the relation between the $\mathrm{dP} / \mathrm{dt}_{\mathrm{MAX}}$ and $\mathrm{EDV}$, and the slope of the preload recruitable stroke work relation. The position of the endsystolic pressure-volume relation was quantified by calculating the ESV intercept at a fixed ESP. The position of the $\mathrm{dP} / \mathrm{dt}_{\mathrm{MAX}}-\mathrm{EDV}$ relation was determined by calculating the intercept at a fixed $\mathrm{EDV}$; this index is denoted as $\mathrm{dP} / \mathrm{dt}_{\mathrm{MAX}, \mathrm{IND}}$. Similarly, the position of the preload recruitable stroke work relation was determined by calculating the intercept at a fixed EDV, $\mathrm{SW}_{\mathrm{IND}}$. As previously described, ${ }^{19}$ the fixed ESP and EDV levels were set retrospectively as the mean ESP and EDV in each group. Diastolic chamber stiffness was quantified by means of exponential regression of the end-diastolic pressure-volume relation..$^{20,21}$

\section{Statistical Analysis}

Pre- and post-CPB data were compared with paired $t$ tests. All data are presented as the mean \pm standard deviation.

\section{Results}

All patients with HF were successfully weaned from CPB after successful mitral valve repair.

In 6 patients the origin of HF was ischemic, and in 4 the origin was nonischemic. In 4 ischemic patients additional CABG was performed; the other 2 patients had irreversible ischemia and did not receive CABG. In 3 patients with severe tricuspid regurgitation, a concomitant restrictive tricuspid ring annuloplasty (ring size, 26) was performed. Six (60\%) patients required inotropic support more than 24 hours postoperatively. However, none of the patients required intra-aortic balloon pump support. The median stay in the intensive care unit in this group was 4 days (range, 2-7 days), with a median total hospital stay of 14 days (range, 7-18 days). All patients could be discharged in good clinical condition from the hospital. The surgical details of both groups are summarized in Table 2. 
TABLE 2. Surgical data

$\begin{array}{cc}\text { RMA group } & \text { Control group } \\ (\mathrm{n}=10) & (\mathrm{n}=13)\end{array}$

CPB time, median (min) 137 (range, 105-287) 104 (range, 60-167) Aox time, median (min) 96 (range, 65-196) 75 (range, 43-129) Pre-MR

AM size $(\mathrm{mm})$

AML size $(\mathrm{mm})$

AM/AML ratio

Ring size

CABG

No. of patients

No. of anastomoses

Length of coaptation

(cm)

Transmitral gradient $(\mathrm{mm} \mathrm{Hg})$

ICU stay, median (d)

Hospital stay, median

(d)

$R M A$, Restrictive mitral annuloplasty; $C P B$, cardiopulmonary bypass; Aox, aortic crossclamp; $M R$, mitral regurgitation; $A M$, mitral annulus; $A M L$, anterior mitral leaflet; $C A B G$, coronary artery bypass grafting; $I C U$, intensive care unit.

\section{Echocardiography}

Mitral regurgitation quantified before the operation was due to annular dilation and systolic restrictive motion of the mitral leaflets and was grade 3 or greater in all patients. After weaning from $\mathrm{CPB}$, intraoperative TEE showed a mean length of coaptation of $8 \pm 2 \mathrm{~mm}$, without residual mitral regurgitation (Table 2 and Figure 1). The mean transmitral diastolic pressure gradient was $2.9 \pm 1.8 \mathrm{~mm} \mathrm{Hg}$ (range, 1.2-7.5 $\mathrm{mm} \mathrm{Hg}$ ). None of the patients showed systolic anterior movement of the anterior leaflet.

\section{Hemodynamic Indices in the RMA and Control Groups}

Data on hemodynamic indices in the RMA and control groups are shown in Table 3. Cardiac output and LVEF remained unchanged after RMA. ESV and EDV tended to decrease, but these changes did not reach statistical significance. The active relaxation (Tau) was significantly improved, from $73 \pm 18$ to $63 \pm 15 \mathrm{~ms}(P=.047)$. Enddiastolic pressure did not increase significantly, and $\mathrm{dP} /$ $\mathrm{dt}_{\mathrm{MAX}}, \mathrm{dP} / \mathrm{dt}_{\mathrm{MIN}}$, and stroke work were also unchanged. Effective arterial elastance (a measure of afterload) was unchanged after RMA. After ring insertion, the pressure gradient across the LV outflow tract was unchanged (from $2.1 \pm 3.3$ to $2.8 \pm 3.3 \mathrm{~mm} \mathrm{Hg}, P=.662$ ). Mechanical dyssynchrony showed a clear tendency to decrease after RMA, but the changes did not reach statistical significance $(P=.084)$. The mechanical efficiency, calculated as stroke work/pressure-volume area, was unchanged after RMA.
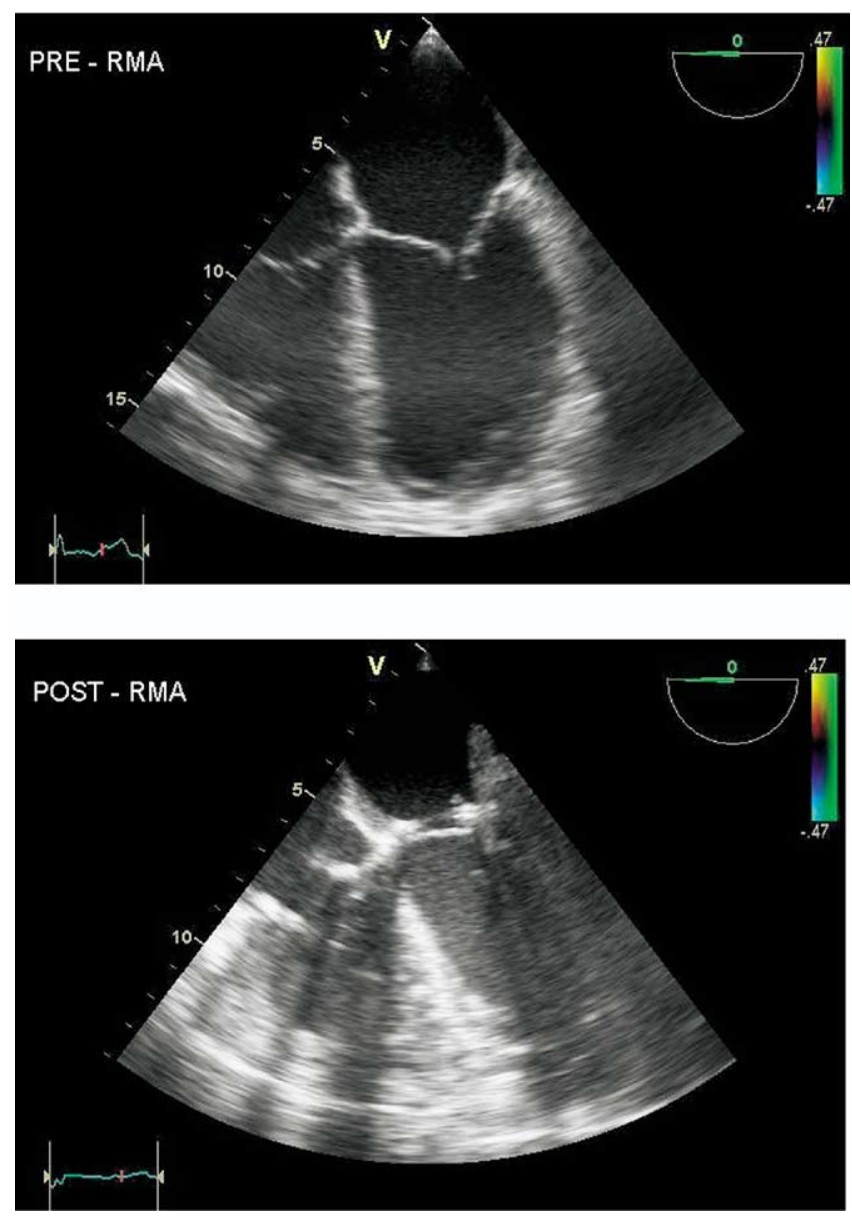

Figure 1. Transesophageal echocardiographic long-axis view before and after restrictive mitral annuloplasty in a 41 -year-old patient with ischemic dilated cardiomyopathy (left ventricular ejection fraction, $20 \%$ ) and severe mitral regurgitation (grade 4 ). Mitral annular dilatation was demonstrated as the relative ratio between the diastolic mitral annular diameter $(5.2 \mathrm{~mm})$ and the diastolic length of the anterior mitral leaflet $(3.6 \mathrm{~mm})$ exceeded 1.3 (1.44). Restrictive mitral annuloplasty (Edwards Physio-ring size 26) was performed, and postoperative mitral leaflet coaptation was $12 \mathrm{~mm}$, with a normal inflow pressure gradient $\mathbf{3 . 5} \mathrm{mm}$ $\mathrm{Hg}$ ) and no residual mitral regurgitation. Additional restrictive tricuspid ring annuloplasty was performed for severe tricuspid regurgitation (grade 3 ).

Similarly, peak LV wall stress ( $356 \pm 91$ to $346 \pm 85 \mathrm{~mm}$ $\mathrm{Hg}, P=.668)$ and end-diastolic wall stress $(64 \pm 30$ to 68 $\pm 17 \mathrm{~mm} \mathrm{Hg}, P=.639$ ) were unchanged. Although baseline values of most parameters in the control group were substantially different from those in the RMA group (consistent with the poor LV function in the RMA group), the changes after surgical intervention were very similar. As in the RMA group, most parameters were unchanged, except Tau, which was significantly improved in both groups, but 
TABLE 3. Hemodynamic data before and after surgical intervention in the RMA and control (CABG) groups

\begin{tabular}{|c|c|c|c|c|c|c|}
\hline & \multicolumn{3}{|c|}{ RMA group $(n=10)$} & \multicolumn{3}{|c|}{ Control group $(n=13)$} \\
\hline & Before & After & $P$ value & Before & After & $P$ value \\
\hline HR (beats/min) & $85 \pm 7$ & $88 \pm 13$ & .491 & $82 \pm 3$ & $86 \pm 8$ & .113 \\
\hline $\mathrm{CO}$ (L/min) & $5.0 \pm 1.8$ & $5.3 \pm 0.9$ & .516 & $4.9 \pm 1.2$ & $5.9 \pm 1.4$ & .193 \\
\hline $\mathrm{SV}(\mathrm{mL})$ & $68 \pm 25$ & $69 \pm 10$ & .905 & $59 \pm 15$ & $69 \pm 19$ & .350 \\
\hline LVEF (\%) & $29 \pm 5$ & $32 \pm 8$ & .315 & $46 \pm 15$ & $52 \pm 18$ & .025 \\
\hline EDV $(\mathrm{mL})$ & $237 \pm 89$ & $226 \pm 52$ & .564 & $142 \pm 52$ & $146 \pm 45$ & .720 \\
\hline ESV (mL) & $171 \pm 67$ & $163 \pm 51$ & .459 & $86 \pm 49$ & $82 \pm 47$ & .190 \\
\hline $\mathrm{ESP}(\mathrm{mm} \mathrm{Hg})$ & $78 \pm 8$ & $79 \pm 14$ & .706 & $74 \pm 13$ & $79 \pm 14$ & .517 \\
\hline $\mathrm{EDP}(\mathrm{mm} \mathrm{Hg})$ & $14 \pm 6$ & $15 \pm 5$ & .356 & $8 \pm 2$ & $14 \pm 5$ & .001 \\
\hline $\mathrm{dP} / \mathrm{dt}_{\mathrm{MAX}}(\mathrm{mm} \mathrm{Hg} / \mathrm{s})$ & $713 \pm 154$ & $775 \pm 197$ & .444 & $992 \pm 282$ & $970 \pm 137$ & .701 \\
\hline $\mathrm{dP} / \mathrm{dt}_{\mathrm{MIN}}(\mathrm{mm} \mathrm{Hg} / \mathrm{s})$ & $-754 \pm 105$ & $-802 \pm 161$ & .351 & $-880 \pm 208$ & $-954 \pm 185$ & .474 \\
\hline $\mathrm{SW}(\mathrm{mm} \mathrm{Hg} \cdot \mathrm{mL})$ & $4299 \pm 1335$ & $4162 \pm 1258$ & .703 & $4400 \pm 1605$ & $5004 \pm 1827$ & .714 \\
\hline PVA $(\mathrm{mm} \mathrm{Hg} \cdot \mathrm{mL})$ & $9422 \pm 3460$ & $9072 \pm 2924$ & .808 & $5873 \pm 2079$ & $6376 \pm 2517$ & .761 \\
\hline SW/PVA & $0.50 \pm 0.17$ & $0.49 \pm 0.15$ & .826 & $0.75 \pm 0.06$ & $0.80 \pm 0.10$ & .306 \\
\hline Tau (ms) & $73 \pm 18$ & $63 \pm 15$ & .047 & $62 \pm 6$ & $51 \pm 5$ & $<.001$ \\
\hline $\mathrm{E}_{\mathrm{A}}(\mathrm{mm} \mathrm{Hg} / \mathrm{mL})$ & $1.39 \pm 0.60$ & $1.29 \pm 0.36$ & .546 & $1.27 \pm 0.20$ & $1.22 \pm 0.38$ & .984 \\
\hline DYSS $(\%)$ & $23.6 \pm 4.3$ & $18.5 \pm 6.7$ & .084 & $17.8 \pm 4.1$ & $17.1 \pm 2.7$ & .217 \\
\hline IFF (\%) & $31.7 \pm 15.4$ & $24.6 \pm 20.2$ & .459 & $19.4 \pm 8.6$ & $17.2 \pm 6.3$ & .127 \\
\hline $\mathrm{E}_{\mathrm{ES}}(\mathrm{mm} \mathrm{Hg} / \mathrm{mL})$ & $0.86 \pm 0.50$ & $0.99 \pm 1.05$ & .688 & $1.31 \pm 0.93$ & $1.26 \pm 0.72$ & .836 \\
\hline $\mathrm{ESV}_{\text {IND }}(\mathrm{mL})$ & $169 \pm 81$ & $161 \pm 68$ & .572 & $82 \pm 50$ & $69 \pm 37$ & .048 \\
\hline $\mathrm{S}-\mathrm{dP}\left(\mathrm{mm} \mathrm{Hg} \cdot \mathrm{s}^{-1} \cdot \mathrm{mL}^{-1}\right)$ & $6.6 \pm 5.4$ & $7.2 \pm 8.9$ & .858 & $8.5 \pm 5.4$ & $7.4 \pm 4.2$ & .583 \\
\hline $\mathrm{dP} / \mathrm{dt}_{\text {MAX, IND }}(\mathrm{mm} \mathrm{Hg} / \mathrm{s})$ & $734 \pm 633$ & $771 \pm 264$ & .832 & $1160 \pm 625$ & $1129 \pm 467$ & .313 \\
\hline S-PRSW (mm Hg) & $64 \pm 54$ & $60 \pm 41$ & .855 & $65 \pm 30$ & $55 \pm 20$ & .594 \\
\hline $\mathrm{SW}_{\text {IND }}(\mathrm{mm} \mathrm{Hg} \cdot \mathrm{mL})$ & $4693 \pm 3140$ & $5093 \pm 3702$ & .725 & $5678 \pm 3532$ & $5473 \pm 2544$ & .985 \\
\hline PWS $(\mathrm{mm} \mathrm{Hg})$ & $356 \pm 91$ & $346 \pm 85$ & .668 & - & - & \\
\hline $\mathrm{WS}_{\mathrm{ED}}(\mathrm{mm} \mathrm{Hg})$ & $64 \pm 30$ & $68 \pm 17$ & .639 & - & - & - \\
\hline $\mathrm{K}_{\mathrm{ED}}\left(\mathrm{mL}^{-1}\right)$ & $0.027 \pm 0.035$ & $0.041 \pm 0.047$ & .542 & $0.021 \pm 0.014$ & $0.038 \pm 0.019$ & .015 \\
\hline
\end{tabular}

$R M A$, Restrictive mitral annuloplasty; $C A B G$, coronary artery bypass grafting; $H R$, heart rate; $C O$, cardiac output; $S V$, stroke volume; $L V E F$, left ventricular ejection fraction; $E D V$, end-diastolic volume; $E S V$, end-systolic volume; $E S P$, end-systolic pressure; $E D P$, end-diastolic pressure; $S W$, stroke work; $P V A$, pressure-volume area; $T a u$, relaxation time constant; $E_{A}$ effective arterial elastance; DYSS, mechanical dyssynchrony; IFF, internal flow fraction; $E_{E S}$, end-systolic elastance; $E S V_{I N D}$, intercept of ESPVR at mean ESP; $S$ - $d P$, slope of $\mathrm{dP} / \mathrm{dt}_{\mathrm{MAX}}-\mathrm{EDV}$ relation; $d P / d t_{M A X}$, IND, intercept of $\mathrm{dP} / \mathrm{dt} \mathrm{MAX}_{\mathrm{MAX}}-\mathrm{EDV}$ relation at mean EDV; $S$-PRSW, slope of the PRSW relation; $S W_{I N D}$, intercept of PRSW relation at mean EDV; $P W S$, peak wall stress; $W S_{E D}$, end-diastolic wall stress; $K_{E D}$ diastolic chamber stiffness constant.

the change in Tau was approximately the same in both groups $(-10.1 \pm 5.0 \mathrm{~ms}$ in the RMA group and $-11.1 \pm$ $5.4 \mathrm{~ms}$ in the control group, $P=.829)$. As a difference, LVEF was significantly improved in the control group $(46 \%$ $\pm 15 \%$ to $52 \% \pm 18 \%, P=.025)$, whereas the increase in the RMA group did not reach statistical significance $(29 \%$ $\pm 5 \%$ to $32 \% \pm 8 \%, P=.315$ ).

\section{Pressure-volume Relations}

Data on pressure-volume relations are shown in Figure 2. Because steady-state hemodynamic indices, as reported in the previous section, are load dependent, we also assessed systolic and diastolic function by means of pressure-volume relations. The slopes of these relations are sensitive and load-independent measures of LV function. Pressure-volume relations were determined from data acquired during temporary preload reduction obtained by means of vena caval occlusion. The mean reduction in EDV was $33 \pm 13$
$\mathrm{mL}$ in the control group and $39 \pm 16 \mathrm{~mL}$ in the RMA group. In both the RMA and control groups, the slopes of the systolic relations (end-systolic elastance, slope of the relation between the $\mathrm{dP} / \mathrm{dt}_{\mathrm{MAX}}$ and $\mathrm{EDV}$, and preload recruitable stroke work relation) did not show significant changes after surgical intervention. Baseline values confirmed poor LV function in the RMA group. With regard to diastolic function, the diastolic chamber stiffness constant increased in both groups (control: $0.021 \pm 0.014$ to $0.038 \pm$ $0.014 \mathrm{~mL}^{-1}, P=.015$; RMA: $0.027 \pm 0.035$ to $0.041 \pm$ $0.047 \mathrm{~mL}^{-1}, P=.542$ ), but the increase did not reach statistical significance in the RMA group.

\section{Discussion}

Mitral valve regurgitation is an important pathology in end-stage HF characterized by annular dilatation and restrictive leaflet motion. ${ }^{22}$ Morbidity and mortality is high if 
PRE - RMA

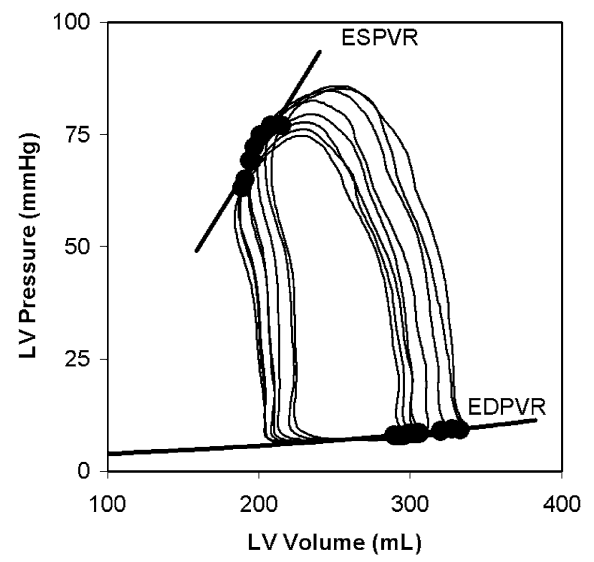

POST - RMA

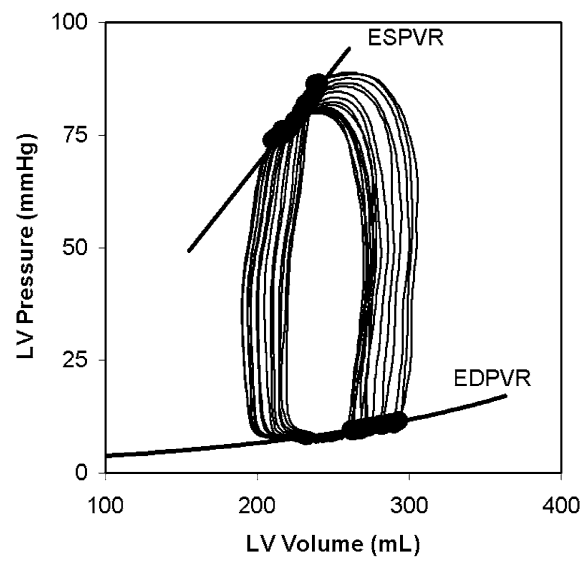

Figure 2. Pressure-volume relations before and after restrictive mitral annuloplasty in a patient with end-stage heart failure. In this patient the end-diastolic pressure-volume relation (EDPVR) demonstrates an increased diastolic stiffness. This was also found in the group as a whole, but the effect was not statistically significant. The slope $\left(E_{E S}\right)$ of the end-systolic pressure-volume relation (ESPVR) in this patient decreased slightly. On average, there was a small increase in $E_{E S}$ in the RMA group, but this change did not reach statistical significance.

mitral regurgitation is treated conservatively. ${ }^{23}$ Grigioni and associates ${ }^{1}$ clearly demonstrated that the severity of mitral regurgitation is directly related to mortality risk.

Therefore it seems reasonable to correct mitral regurgitation in patients with end-stage HF to improve prognosis. Currently, mitral annuloplasty is not routinely performed in these patients because substantial mortality and high recurrence rates are reported, and no evidence from randomized studies is available., ${ }^{7,24}$ However, several recent studies have shown relatively low operative mortality and suggest improved long-term survival after stringent RMA. ${ }^{9,11,25}$ Unfortunately, insights in the acute effects of RMA on systolic and diastolic LV performance are still limited, and concerns are raised about possible adverse acute effects on systolic and diastolic LV function, which would limit application of this approach in patients with end-stage HF. The aim of our study was therefore to quantify these effects by use of load-independent pressure-volume indices.

We found unchanged systolic function after RMA. This is interesting because earlier studies had predicted adverse effects, which would be the result of an afterload mismatch created by closure of a low-resistance runoff into the left atrium. However, this "pop-off" effect might not exist, and the high mortality in earlier studies appears mainly related to loss of LV function by disruption of the subvalvular apparatus because in that time, valve replacement (rather than repair) was mostly performed. ${ }^{26}$ The effect on systolic function might also result from acute remodeling of the base of the heart because of the undersized ring. Bolling and colleagues $^{27}$ argue that this would improve systolic function; however, a study by David and coworkers ${ }^{28}$ implies a negative effect on systolic function because an undersized ring presumably impairs stretching and shortening of the proximal part of the basoconstrictor muscles (similar to a rigid ring). In our study we did not find any evidence for an altered (either reduced or improved) systolic function. In addition, systolic anterior motion of the anterior leaflet leading to LV outflow tract obstruction was not found in our series.

With regard to diastolic function, we found an increase in diastolic chamber stiffness. This effect was present in both groups, but it was only statistically significant in the control patients. This increase in diastolic chamber stiffness is probably mainly an effect of cardioplegic arrest, leading to interstitial myocardial edema. ${ }^{29} \mathrm{LV}$ wall stress was unchanged after RMA, which is consistent with largely unchanged EDV and ESP.

The number of studies in which the effects of RMA on LV performance are evaluated is limited. Several studies show improved LVEF and reduced EDV. ${ }^{8,11,25,30}$ Bishay and colleagues ${ }^{31}$ reported improved LV function and reversed remodeling at 2 years' follow-up in patients with severe LV dysfunction. However, this group was heterogeneous, and the patients underwent either mitral annuloplasty with various techniques or mitral valve replacement. Bax and associates ${ }^{9}$ studied patients who strictly underwent RMA and showed that reverse remodeling of the left ventricle is a gradual and time-dependent process. These results are consistent with our findings, which show no acute effects on LV performance after RMA. Interestingly, our results show a clear tendency for a reduced mechanical dyssynchrony after RMA. This index has recently been 
shown to be a very sensitive marker of LV dysfunction, ${ }^{17}$ and potentially this improvement might contribute to beneficial long-term effects.

\section{Limitations}

The sample size in our study was relatively small, and potentially positive effects on systolic function might be demonstrated in a larger group of patients. However, we performed pre- and post-CPB measurements in each patient, which optimizes the statistical power to detect possible effects of the surgical intervention. In addition, the RMA group was heterogeneous because in 4 patients additional CABG was performed. This subgroup was too small for meaningful statistical analysis, but the effects on pressurevolume relations in these patients did not appear to be different compared with the effects in the whole group. Furthermore, beneficial effects on LV systolic function in these patients would not be expected early after surgical intervention because the effects of revascularization on hibernating myocardium often occur later after the operation. ${ }^{32}$ Measurements of global LV function were performed immediately after the operation with an open chest and during inotropic support. The confounding effects of inotropic support were limited by also performing the measurements before the operation during inotropic support, but possible altered $\beta$-receptor sensitivity cannot be excluded. Assessment of regional function and of long-term effects under physiologic conditions requires further study.

\section{Conclusion}

Mitral valve repair by means of RMA effectively restores mitral valve leaflet coaptation in patients with end-stage HF and severe mitral regurgitation, without significant acute changes in baseline hemodynamics and LV systolic and diastolic function. Our findings support the use of this approach, even in patients with severely depressed LV function, in view of the expected beneficial long-term results.

\section{References}

1. Grigioni F, Enriquez-Sarano M, Zehr KJ, Bailey KR, Tajik AJ. Ischemic mitral regurgitation: long-term outcome and prognostic implications with quantitative Doppler assessment. Circulation. 2001;103: $1759-64$

2. Hueb AC, Jatene FB, Moreira LF, Pomerantzeff PM, Kallas E, de Oliveira SA. Ventricular remodeling and mitral valve modifications in dilated cardiomyopathy: new insights from anatomic study. $J$ Thorac Cardiovasc Surg. 2002;124:1216-24.

3. Carpentier A. Cardiac valve surgery-the "French correction." J Thorac Cardiovasc Surg. 1983;86:323-37.

4. Aikawa K, Sheehan FH, Otto CM, Coady K, Bashein G, Bolson EL. The severity of functional mitral regurgitation depends on the shape of the mitral apparatus: a three-dimensional echo analysis. J Heart Valve Dis. 2002;11:627-36.

5. Dion R. Ischemic mitral regurgitation: when and how should it be corrected? J Heart Valve Dis. 1993;2:536-43.
6. Mann DL. Mechanisms and models in heart failure: a combinatorial approach. Circulation. 1999;100:999-1008.

7. Chen FY, Adams DH, Aranki SF, Collins JJ Jr, Couper GS, Rizzo RJ, et al. Mitral valve repair in cardiomyopathy. Circulation. 1998; 98(suppl):II124-7.

8. Bolling SF, Pagani FD, Deeb GM, Bach DS. Intermediate-term outcome of mitral reconstruction in cardiomyopathy. $J$ Thorac Cardiovasc Surg. 1998;115:381-6.

9. Bax JJ, Braun J, Somer ST, Klautz R, Holman ER, Versteegh MI, et al. Restrictive annuloplasty and coronary revascularization in ischemic mitral regurgitation results in reverse left ventricular remodeling. Circulation. 2004;110(suppl):II103-8.

10. Dreyfus G, Milaiheanu S. Mitral valve repair in cardiomyopathy. J Heart Lung Transplant. 2000;19(suppl):S73-6.

11. Bolling SF, Deeb GM, Brunsting LA, Bach DS. Early outcome of mitral valve reconstruction in patients with end-stage cardiomyopathy. J Thorac Cardiovasc Surg. 1995;109:676-82.

12. Thomas JD. How leaky is that mitral valve? Simplified Doppler methods to measure regurgitant orifice area. Circulation. 1997;95:54850 .

13. Calafiore AM, Teodori G, Mezzetti A, Bosco G, Verna AM, Di Giammarco G, et al. Intermittent antegrade warm blood cardioplegia. Ann Thorac Surg. 1995;59:398-402.

14. Carpentier AF, Lessana A, Relland JY, Belli E, Mihaileanu S, Berrebi AJ, et al. The "physio-ring": an advanced concept in mitral valve annuloplasty. Ann Thorac Surg. 1995;60:1177-85.

15. Tulner SA, Klautz RJ, Rijk-Zwikker GL, Engbers FH, Bax JJ, Baan J, et al. Perioperative assessment of left ventricular function by pressurevolume loops using the conductance catheter method. Anesth Analg. 2003;97:950-7.

16. Steendijk P, Staal E, Jukema JW, Baan J. Hypertonic saline method accurately determines parallel conductance for dual-field conductance catheter. Am J Physiol Heart Circ Physiol. 2001;281:H755-63.

17. Steendijk P, Tulner SA, Schreuder JJ, Bax JJ, Van Erven L, van der Wall EE, et al. Quantification of left ventricular mechanical dyssynchrony by conductance catheter in heart failure patients. Am J Physiol Heart Circ Physiol. 2004;286:H723-30.

18. Arts T, Bovendeerd PH, Prinzen FW, Reneman RS. Relation between left ventricular cavity pressure and volume and systolic fiber stress and strain in the wall. Biophys J. 1991;59:93-102.

19. Steendijk P, Baan J Jr, van der Velde ET, Baan J. Effects of critical coronary stenosis on global systolic left ventricular function quantified by pressure-volume relations during dobutamine stress in the canine heart. J Am Coll Cardiol. 1998;32:816-26.

20. Mandinov L, Eberli FR, Seiler C, Hess OM. Diastolic heart failure. Cardiovasc Res. 2000;45:813-25.

21. Sagawa K. The end-systolic pressure-volume relation of the ventricle: definition, modifications and clinical use. Circulation. 1981;63: 1223-7.

22. Kwan J, Shiota T, Agler DA, Popovic ZB, Qin JX, Gillinov MA, et al. Geometric differences of the mitral apparatus between ischemic and dilated cardiomyopathy with significant mitral regurgitation: real-time three-dimensional echocardiography study. Circulation. 2003;107: 1135-40.

23. Trichon BH, Glower DD, Shaw LK, Cabell CH, Anstrom KJ, Felker GM, et al. Survival after coronary revascularization, with and without mitral valve surgery, in patients with ischemic mitral regurgitation. Circulation. 2003;108(suppl):II103-10.

24. Tahta SA, Oury JH, Maxwell JM, Hiro SP, Duran CM. Outcome after mitral valve repair for functional ischemic mitral regurgitation. $J$ Heart Valve Dis. 2002;11:11-8.

25. Gummert JF, Rahmel A, Bucerius J, Onnasch J, Doll N, Walther T, et al. Mitral valve repair in patients with end stage cardiomyopathy: who benefits? Eur J Cardiothorac Surg. 2003;23:1017-22.

26. Bonchek LI, Olinger GN, Siegel R, Tresch DD, Keelan MH Jr. Left ventricular performance after mitral reconstruction for mitral regurgitation. J Thorac Cardiovasc Surg. 1984;88:122-7.

27. Bolling SF, Smolens IA, Pagani FD. Surgical alternatives for heart failure. J Heart Lung Transplant. 2001;20:729-33. 
28. David TE, Komeda M, Pollick C, Burns RJ. Mitral valve annuloplasty: the effect of the type on left ventricular function. Ann Thorac Surg. 1989;47:524-7.

29. Ericsson AB, Takeshima S, Vaage J. Simultaneous antegrade and retrograde delivery of continuous warm blood cardioplegia after global ischemia. J Thorac Cardiovasc Surg. 1998;115:716-22.

30. Rothenburger M, Rukosujew A, Hammel D, Dorenkamp A, Schmidt C, Schmid C, et al. Mitral valve surgery in patients with poor left ventricular function. Thorac Cardiovasc Surg. 2002;50:351-4.

31. Bishay ES, McCarthy PM, Cosgrove DM, Hoercher KJ, Smedira NG, Mukherjee D, et al. Mitral valve surgery in patients with severe left ventricular dysfunction. Eur J Cardiothorac Surg. 2000;17:213-21.

32. Bax JJ, Visser FC, Poldermans D, Elhendy A, Cornel JH, Boersma E, et al. Time course of functional recovery of stunned and hibernating segments after surgical revascularization. Circulation. 2001; 104(suppl):I314-8.

\section{JTCVS On-Line Manuscript Submission and Review}

\section{Please visit http://www.editorialmanager.com/jtcvs/}

Effective September 15, 2001, authors and reviewers may submit manuscripts and reviews electronically via Editorial Manager, our new Web-based system with full electronic submission, review, and status update capabilities.

As we move from paper to electronic submissions, the Editorial Office will make proxy submissions of all manuscripts accompanied by a diskette containing the electronic files of the text, tables, and figures. Editors, authors, and reviewers will receive automatic e-mails when significant events occur.

We strongly encourage all authors and reviewers to use Editorial Manager. Although we will continue to accommodate the submission of paper manuscripts for some months, our goal is to be completely electronic within 9 to 12 months.

All individuals currently in our database for whom we have e-mail addresses will receive via e-mail a system-assigned username and password that can be used to log in to the system without prior registration. All those not receiving the e-mail must register the first time they use the system.

As with any broad systemic change, the conversion to the new system will take some time to complete. We ask your patience as we replace our in-office database with the new system. We also encourage you to take advantage of the speed and efficiency that the new system will provide for us all: editor, author, reviewer, and publisher. 